\title{
Aarroo Caracterização dos casos confirmados de dengue por meio da técnica de linkage de bancos de dados, para avaliar a circulação viral em Belo Horizonte, 2009-2014*
}

doi: 10.5123/S1679-49742020000300016

\author{
Characterization of dengue cases confirmed using the database linkage technique: \\ assessment of virus circulation in Belo Horizonte, Brazil, 2009-2014
Características de los casos confirmados de dengue utilizando la técnica de enlace de bases de datos, para evaluar la circulación viral en la ciudad de Belo Horizonte, Brasil, 2009-2014

\footnotetext{
Ana Carolina Lemos Rabelo' - (1) orcid.org/0000-0002-5247-9266

Frederico Figueiredo Amâncio² - (1) orcid.org/0000-0002-5732-7173

Carla Sayuri Fogaça Oiko ${ }^{3}$ - (1) orcid.org/0000-0001-6556-7989

Marcela Lencine Ferraz ${ }^{4}$ - (1) orcid.org/0000-0003-1560-5777

Mariângela Carneiro ${ }^{5}$ - ๑ orcid.org/0000-0002-9390-7714
}

'Universidade Federal de Minas Gerais, Programa de Pós-Graduação em Ciências da Saúde, Belo Horizonte, MG, Brasil ${ }^{2}$ Fundação Hospitalar do Estado de Minas Gerais, Hospital João XXIII, Belo Horizonte, MG, Brasil

${ }^{3}$ Secretaria Municipal de Saúde de Belo Horizonte, Gerência de Zoonoses Norte, Belo Horizonte, MG, Brasil

${ }^{4}$ Secretaria de Estado de Saúde de Minas Gerais, Superintendência de Vigilância Epidemiológica, Belo Horizonte, MG, Brasil

${ }^{5}$ Universidade Federal de Minas Gerais, Departamento de Parasitologia, Belo Horizonte, MG, Brasil

\section{Resumo}

Objetivo: descrever a circulação viral de dengue em Belo Horizonte, Brasil, de 2009 a 2014. Métodos: trata-se de estudo de série de casos de dengue infectados por diferentes sorotipos do vírus, identificados por isolamento viral ou RT-PCR; foi realizado linkage das bases de dados do Sistema de Informação de Agravos de Notificação (Sinan), do Sistema de Informações Hospitalares do Sistema Único de Saúde (SIH/SUS) e do Gerenciador de Ambiente Laboratorial (GAL). Resultados: foram relacionados $91,1 \%$ dos registros $(n=775)$; entre os casos $(n=851), 60,4 \%(n=514)$ foram confirmados como DENV-1, 22,1\% $(n=188)$ como DENV-4, 9,8\% $(n=83)$ como DENV-2 e 7,7\% $(n=66)$ como DENV-3; DENV-2 apresentou maior percentual de casos graves (4,5\%). Conclusão: DENV-1 prevaleceu e circulou em todos os anos avaliados.

Palavras-chave: Dengue; Vírus da Dengue; Monitoramento Epidemiológico; Base de Dados.

\footnotetext{
*Artigo derivado da dissertação intitulada 'Linkage de bancos de dados e análise descritiva dos casos confirmados de dengue por isolamento viral e reação em cadeia da polimerase no município de Belo Horizonte, 2009-2014', defendida por Ana Carolina Lemos Rabelo junto ao Programa de Pós-Graduação em Ciências da Saúde, Área de Concentração, Infectologia e Medicina Tropical da Universidade Federal de Minas Gerais (UFMG), em 2018.
}

Endereço para correspondência:

Ana Carolina Lemos Rabelo - Instituto Oswaldo Cruz, Instituto René Rachou, World Mosquito Program, Av. Augusto de Lima, $\mathrm{n}^{\circ}$ 1715, Anexo 31, Barro Preto, Belo Horizonte, MG, Brasil. CEP:30190-002

E-mail:aclrabelo@gmail.com 


\section{Introdução}

A dengue é uma doença febril aguda, com espectro clínico variável desde formas assintomáticas e oligossintomáticas até quadros graves, podendo evoluir para óbito, ${ }^{1}$ sendo considerada uma das arboviroses de maior importância global. ${ }^{2} 0$ vírus da dengue (DENV) é transmitido ao homem por mosquitos do gênero Aedes sp. e possui quatro sorotipos distintos: DENV-1, DENV-2, DENV-3 e DENV-4. ${ }^{1}$ No Brasil, desde 2010, os quatro sorotipos se encontram em circulação. ${ }^{1}$

No país, registra-se a ocorrência de dengue desde 1846, com a primeira epidemia documentada em 1981-1982 (Boa Vista, Roraima). ${ }^{1}$ Em Belo Horizonte, os primeiros casos foram registrados em $1996 .{ }^{3}$ A introdução dos quatro sorotipos deu-se de forma progressiva, ${ }^{4}$ e, de 2009 a 2014 , todos os sorotipos circularam no município. ${ }^{5}$ Em Belo Horizonte, a identificação viral é realizada pela Fundação Ezequiel Dias (Funed) - laboratório de referência de Minas Gerais -, por técnicas de isolamento viral e transcrição reversa seguida da reação em cadeia da polimerase (RT-PCR). Os resultados laboratoriais são inseridos no Gerenciador de Ambiente Laboratorial (GAL).

\section{As epidemias de dengue ocasionam importante carga aos serviços de saúde eà economia. 0 controle da doença e a redução da densidade do vetor permanecem como desafios.}

No Brasil, todo caso suspeito de dengue deve ser registrado no Sistema de Informação de Agravos de Notificação (Sinan). ${ }^{1}$ Os casos que exigem internação são registrados no Sistema de Informações Hospitalares do Sistema Único de Saúde (SIH/SUS). ${ }^{1}$ Estes sistemas não possuem um campo identificador unívoco, impossibilitando a identificação direta dos registros de um mesmo caso entre suas bases distintas.

A técnica de relacionamento, conhecida como linkage de bancos de dados, tem sido utilizada nas análises de Saúde Pública para detectar e excluir registros duplicados, integrar e agregar informações dos diferentes sistemas. ${ }^{6,7}$ Dessa forma, é possivel identificar e resgatar informações presentes em um sistema e ausentes ou incompletas em outro, ${ }^{8}$ construindo um banco de dados único e mais completo. ${ }^{6,7,9}$
As epidemias de dengue ocasionam importante carga aos serviços de saúde e à economia. 0 controle da doença e a redução da densidade do vetor permanecem como desafios. A gravidade dos sintomas, assim como o risco de epidemias, pode depender do sorotipo em circulação, sendo assim importante avaliar e descrever a dinâmica das infecções causadas pelo DENV.

Este estudo teve por objetivo descrever a circulação viral de dengue em Belo Horizonte, no período de 2009 a 2014.

\section{Métodos}

Trata-se de estudo de série de casos de dengue.

Belo Horizonte é a capital do estado de Minas Gerais, localizado na região Sudeste do Brasil. Em 2010, o município contava uma população de 2.375.151 habitantes ${ }^{10}$ dividida em nove regiões administrativas (Barreiro, Centro Sul, Leste, Nordeste, Noroeste, Norte, Oeste, Pampulha e Venda Nova) coincidentes com os territórios de Diretorias Regionais de Saúde. As Diretorias Regionais de Saúde se subdividem em 152 áreas de abrangência dos Centros de Saúde.

Foram incluídos todos os casos de dengue que apresentaram amostras positivas para DENV, analisadas por meio de RT-PCR e/ou isolamento viral, no período de 2009 a 2014, em Belo Horizonte.

Para a identificação do sorotipo - por RT-PCR e/ou isolamento viral -, foram coletadas amostras de sangue até $05^{\circ}$ dia de início dos sintomas, encaminhadas à Funed.

Também foram avaliados a sorologia e 0 teste rápido de pesquisa do antígeno NS1 (NS: do inglês non structural) como métodos de diagnóstico laboratorial. Tais métodos não permitem a identificação do sorotipo e foram avaliados como variáveis de interesse, não sendo utilizados como critério de inclusão. A sorologia é realizada após o $6^{\circ}$ dia de início de sintomas e a pesquisa por NS1 até $05^{\circ}$ dia. Em Belo Horizonte, 0 teste rápido NS1 é utilizado como triagem de amostras para isolamento viral. As amostras positivas e $10 \%$ das amostras negativas são encaminhadas à Funed, com cota máxima de 90 amostras/mês.

Foi realizado linkage das bases de dados do Sinan, do SIH/SUS e do GAL. As três bases de dados analisadas referiam-se ao período de $1^{\circ}$ de janeiro de 2009 a 31 de dezembro de 2014, sendo o total de registros: 263.995 (Sinan), 4.215 (SIH/SUS) e 4.392 (GAL). 
Foi realizada preparação manual prévia dos bancos, quanto à padronização e codificação dos campos. Foram aplicadas as mesmas codificações para os campos de 'sexo' e o mesmo formato de datas. Os campos 'raça/cor da pele', 'metodologia' e 'sorotipo' foram transformados em caracteres numéricos.

Os bancos foram importados para o Sistema Gerenciador de Banco de Dados MySQL (versão 5.7), utilizando-se ferramenta Front 5.2. As bases utilizadas possuíam alguns identificadores comuns e, nessa fase, foi criada chave com as variáveis 'nome da pessoa', 'nome da mãe' e 'data de nascimento'.

Considerando-se o tamanho das bases de dados empregadas, a acurácia das técnicas de relacionament $0^{8}$ e a utilização da revisão manual para complementar a estratégia, decidiu-se pelo uso do linkage determinístico (baseado na concordância exata).

Foi realizado INNER JOIN entre as bases, na sequência GAL $\leftrightarrow$ Sinan e GAL $\leftrightarrow$ SIH/SUS, para junção das bases e identificação dos registros comuns. ${ }^{11}$ Para os nomes não pareados, considerando-se que havia valores faltantes ou mal preenchidos, e na tentativa de novo pareamento, reduziu-se a integridade da chave desprezando-se variáveis, na seguinte ordem: (i) Ano do nascimento; (ii) Mês do nascimento; (iii) Dia do nascimento; (iv) $3^{\circ}$ Sobrenome da mãe; (v) $3^{\circ}$ Sobrenome da pessoa; (vi) $2^{\circ}$ Sobrenome da mãe; (vii) $2^{\circ}$ Sobrenome da pessoa; (viii) Nome da mãe; e (ix) Nome da pessoa.

Os registros não relacionados foram revisados manualmente, por um pesquisador (ACLR), para tentativa de pareamento.

Os dados de monitoramento viral foram extraídos do GAL; os de internação, do SIH/SUS; e os demais (sociodemográficos, classificação final, diagnóstico laboratorial, encerramento, evolução, manifestações clínicas e outros), do Sinan.

As variáveis estudadas e suas categorias foram:

a) sexo (masculino; feminino);

b) faixa etária (em anos: $\leq 10 ; 11-20 ; 21-30 ; 31-40$; 41-50; > 50);

c) raça/cor da pele (branca; preta; parda; amarela);

d) escolaridade (analfabeto; ensino fundamental incompleto/completo; ensino médio incompleto/ completo; ensino superior incompleto/completo);

e) sorotipo (DENV-1; DENV-2; DENV-3; DENV-4);

f) técnica de identificação do vírus (isolamento viral; RT-PCR); g) classificação final (dengue clássico; dengue com complicações; febre hemorrágica da dengue; dengue; dengue com sinais de alarme; descartado);

h) critério de encerramento do caso (laboratorial; clínico-epidemiológico);

i) evolução (cura; óbito por dengue; óbito por outras causas);

j) resultado da sorologia e do teste rápido NS1 (reagente; não reagente; inconclusivo);

k) internação (sim; não);

l) tempo entre início de sintomas e internação; e

m) dias de permanência em internação (média; desvio-padrão [DP]; mediana).

Foram utilizadas medidas-resumo (média; mediana; DP) para variáveis quantitativas. Aplicou-se o teste do qui-quadrado de Pearson $\left(X^{2}\right)$ para verificar associação entre as variáveis 'sexo' e 'faixa etária' com os sorotipos do vírus, com nível de significância de 5\%.

No período do estudo, ocorreu mudança na classificação de caso de dengue adotada pelo Ministério da Saúde. Para solucionar essa questão, a população do estudo foi dividida em dois momentos: entre 2009 e 2013, os casos eram classificados como dengue clássico (DC), dengue com complicações (DCC), febre hemorrágica da dengue (FHD) e síndrome do choque da dengue (SCD); a partir de 2014, os casos foram classificados como dengue (D), dengue com sinais de alarme (DcSA) e dengue grave (DG). Para a análise da dinâmica da circulação viral em Belo Horizonte, os casos de DC e D foram agrupados como 'dengue clássico' e os casos de DCC, FHD, SCD, DcSA e DG foram agrupados como 'dengue não clássico'.

Os bancos de dados foram armazenados e analisados com uso do software SPSS ${ }^{\mathrm{TM}}$ versão 20.

0 estudo foi aprovado pelo Comitê de Ética em Pesquisa da Universidade Federal de Minas Gerais (CEP/UFMG), Certificado de Apresentação para Apreciação Ética (CAAE) $\mathrm{n}^{0}$ 62191116.1.0000.5149, em 7 de dezembro de 2016. os dados nominais foram utilizados somente para 0 relacionamento das bases de dados, preservando-se a privacidade dos participantes.

\section{Resultados}

Entre 2009 e 2014, foram notificados no Sinan 250.632 casos suspeitos de dengue em Belo Horizonte; confirmados 163.947 casos; as maiores notificações foram observadas em 2010 (51.755) e 2013 (96.121). 
No mesmo período, foram enviadas à Funed 4.376 amostras de sangue para tentativa de identificação do DENV.

Foram incluídos no estudo 851 casos confirmados por isolamento viral e/ou RT-PCR, 796 (93,5\%) deles registrados no Sinan. Todos os 47 casos registrados no SIH/SUS também estavam registrados no Sinan. 0 fluxograma de seleção dos casos está representado na
Figura 1. A Tabela 1 apresenta as principais características sociodemográficas desses casos. Destaca-se que $52,6 \%$ dos casos eram do sexo feminino; $5,8 \%$ dos casos apresentavam idade menor ou igual a 10 anos, $72,2 \%$ tinham de 11 a 50 anos e 19,6\% idade superior a 50 anos, resultando em uma idade média dos casos de 34,8 anos (desvio-padrão: 17,8 anos).

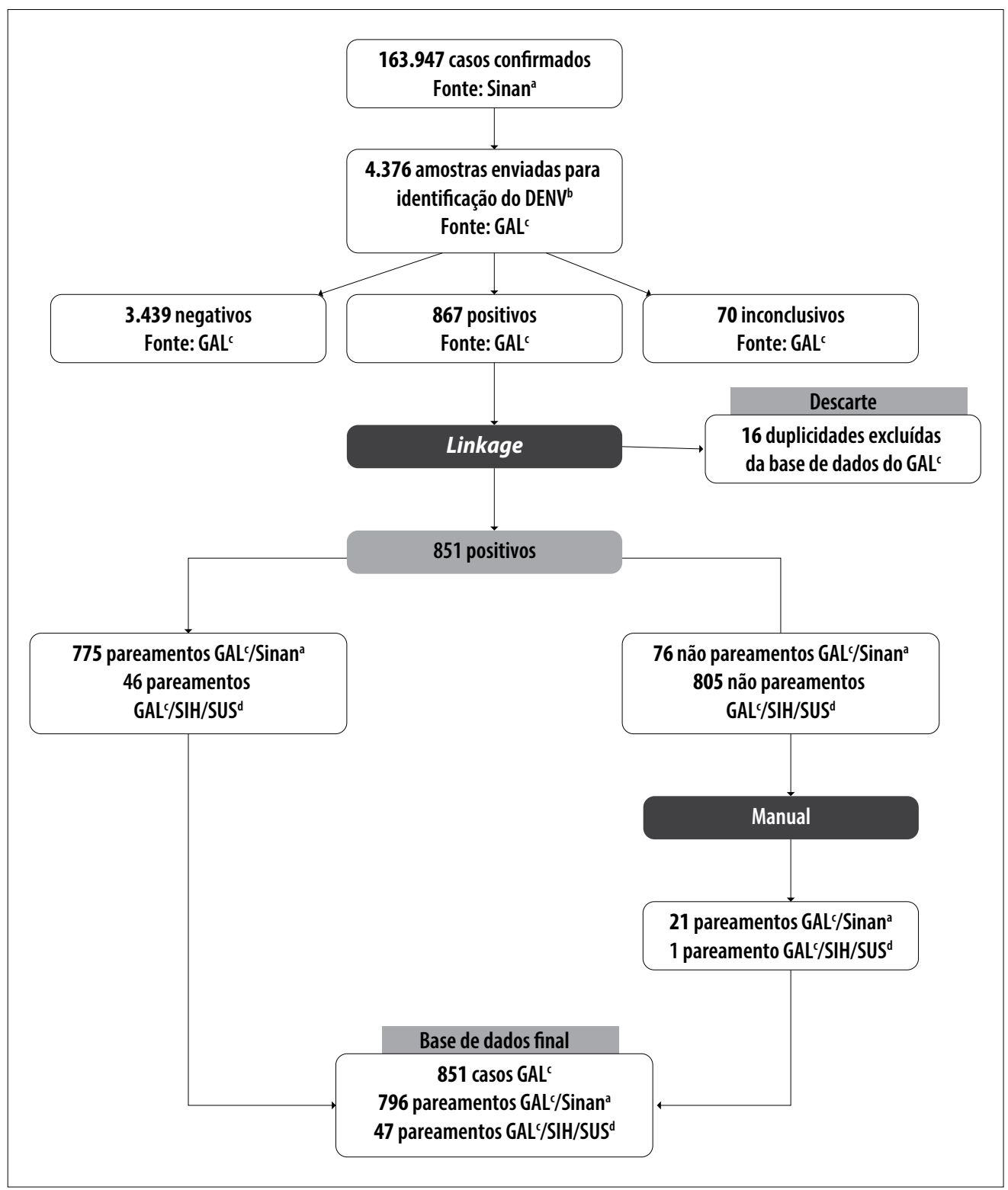

Figura 1 - Relacionamento de bancos de dados, Belo Horizonte, Minas Gerais, 2009-2014

a) Sinan:Sistema de Informação de Agravos de Notificação.

b) DENV: vírus da dengue.

c) GAL:Gerenciador de Ambiente Laboratorial.

d) SIH/SUS: Sistema de Informações Hospitalares do Sistema Único de Saúde. 
Tabela 1 - Características sociodemográficas dos casos confirmados de dengue por isolamento viral e RT-PCR, ${ }^{\text {a }}$ Belo Horizonte, Minas Gerais, 2009-2014

\begin{tabular}{|c|c|c|}
\hline Característica & $\mathrm{n}=851$ & $\%$ \\
\hline \multicolumn{3}{|l|}{ Sexo } \\
\hline Feminino & 448 & 52,6 \\
\hline Masculino & 403 & 47,4 \\
\hline \multicolumn{3}{|l|}{ Idade (variável contínua) } \\
\hline Média \pm desvio-padrão & \multicolumn{2}{|c|}{$34,8 \pm 17,8$} \\
\hline Mediana (intervalos interquartis) & \multicolumn{2}{|c|}{$31,6(21,6 ; 47,1)$} \\
\hline \multicolumn{3}{|l|}{ Idade (em anos - variável categórica) } \\
\hline$\leq 10$ & 49 & 5,8 \\
\hline $11-20$ & 155 & 18,2 \\
\hline $21-30$ & 197 & 23,1 \\
\hline $31-40$ & 151 & 17,7 \\
\hline $41-50$ & 112 & 13,2 \\
\hline$>50$ & 167 & 19,6 \\
\hline Ignorado/branco & 20 & 2,4 \\
\hline \multicolumn{3}{|l|}{ Raça/cor da pele } \\
\hline Branca & 214 & 25,2 \\
\hline Preta & 52 & 6,1 \\
\hline Parda & 190 & 22,3 \\
\hline Amarela & 6 & 0,7 \\
\hline Ignorada/em branco & 389 & 45,7 \\
\hline \multicolumn{3}{|l|}{ Escolaridade } \\
\hline Analfabeto & 80 & 9,4 \\
\hline Ensino fundamental incompleto & 113 & 13,3 \\
\hline Ensino fundamental completo & 45 & 5,3 \\
\hline Ensino médio incompleto & 51 & 6,0 \\
\hline Ensino médio completo & 103 & 12,2 \\
\hline Ensino superior incompleto & 22 & 2,6 \\
\hline Ensino superior completo & 24 & 2,8 \\
\hline Ignorada/em branco & 413 & 48,5 \\
\hline \multicolumn{3}{|l|}{ Monitoramento viral - sorotipo } \\
\hline DENV-1 ${ }^{b}$ & 514 & 60,4 \\
\hline DENV- $2^{b}$ & 83 & 9,8 \\
\hline DENV- $3^{b}$ & 66 & 7,7 \\
\hline DENV-4 ${ }^{\mathrm{b}}$ & 188 & 22,1 \\
\hline \multicolumn{3}{|l|}{ Técnica de identificação do vírus } \\
\hline Isolamento viral & 572 & 67,2 \\
\hline RT-PCRa & 170 & 20,0 \\
\hline Ignorado/em branco & 109 & 12,8 \\
\hline \multicolumn{3}{|l|}{ Classificação final } \\
\hline Dengue clássico & 590 & 69,3 \\
\hline Dengue com complicações & 6 & 0,7 \\
\hline Febre hemorrágica da dengue & 3 & 0,4 \\
\hline Dengue & 128 & 15,0 \\
\hline Dengue com sinais de alarme & 1 & 0,1 \\
\hline Descartado & 49 & 5,8 \\
\hline Ignorada/em branco & 74 & 8,7 \\
\hline \multicolumn{3}{|l|}{ Critério de encerramento } \\
\hline Laboratório & 693 & 81,4 \\
\hline Clínico-epidemiológico & 85 & 10,0 \\
\hline Ignorado/em branco & 73 & 8,6 \\
\hline
\end{tabular}


Tabela 1 - Características sociodemográficas dos casos confirmados de dengue por isolamento viral e RT-PCR aça Belo Horizonte, Minas Gerais, 2009-2014

\begin{tabular}{lcc}
\hline Característica & $\mathbf{n}=851$ & $\%$ \\
\hline Evolução & & 77,8 \\
\hline Cura & 662 & 0,7 \\
Óbito por dengue & 6 & 0,1 \\
Óbito por outras causas & 1 & 21,4 \\
Ignorada/em branco & 182 & 35,5 \\
\hline Sorologia & & 3,8 \\
\hline Reagente & 302 & 0,1 \\
Não reagente & 32 & 60,6 \\
Inconclusivo & 1 & 43,4 \\
Ignorada/em branco & 516 & 2,0 \\
\hline Teste rápido NS1' & & 54,6 \\
\hline Reagente & 369 & \\
Não reagente & 17 & 5,5 \\
Ignorado/em branco & 465 & 94,5 \\
\hline Internação & & \\
\hline Sim & 47 & \\
Não & 804 & \\
\hline
\end{tabular}

a) RT-PCR: reação da transcriptase reversa, seguida de reação em cadeia da polimerase.

b) Sorotipos do vírus da dengue: $1,2,3$ e 4 .

c) Pesquisa do antígeno NS1.

O sorotipo DENV-1 foi identificado em 514 casos (60,4\%); o DENV-4, em 188 (22,1\%); o DENV-2, em 83 $(9,8 \%)$; e o DENV-3, em 66 (7,7\%). Do total de amostras positivas, $67,2 \%$ foram confirmadas por isolamento viral. Nos anos de 2009 e 2010, circularam três sorotipos em Belo Horizonte: DENV-1, DENV-2 e DENV-3. Em 2011, somente o sorotipo DENV-1 foi isolado. No período de 2012 a 2014, foram isolados os sorotipos DENV-1 e DENV-4 (Figura 2). Em 2010 e 2013, anos epidêmicos, identificou-se a circulação de três e dois sorotipos, respectivamente.

Entre os casos identificados com os sorotipos DENV-1 e DENV-3, a faixa etária mais frequente foi a de 11 a 30 anos (DENV-1, 44,9\%; DENV-3, 43,8\%). DENV-2 foi mais identificado em pessoas com 11 a 30 anos (41,5\%), enquanto o sorotipo DENV-4, na faixa etária de 31 a 50 anos (36,0\%). Não houve diferença estatisticamente significativa em relação a 'sexo' e 'faixa etária' e o sorotipo circulante (Tabela 2).

Em 2009, o sorotipo DENV-3 foi predominante em pessoas com idade inferior a 10 anos, entre 21-30 anos e entre 41-50 anos. Nas faixas etárias de 11 a 20 anos e acima de 50 anos, predominou o DENV-2. Em 2010, em todas as faixas etárias, o maior percentual de sorotipo identificado foi o DENV-1. Em 2011, o sorotipo viral só foi identificado em pessoas com idade entre 11 e 50 anos, com isolamento apenas do DENV-1. Em 2012, na faixa de idade igual ou inferior a 10 anos, o sorotipo identificado foi o DENV-4, e nas faixas etárias acima dos 11 anos, 0 sorotipo predominante foi 0 DENV-1. Em 2013, na faixa de idade menor que 30 anos, predominou o sorotipo DENV-1, e na maior que 31 anos, o sorotipo predominante foi o DENV-4. No último ano avaliado, 2014, o sorotipo predominante em todas as idades foi 0 DENV-1 (Figura 3).

Entre 2009 e 2014, 718 casos (98,6\%) foram classificados como dengue clássico e 10 (1,4\%) como dengue com complicações, febre hemorrágica da dengue e dengue com sinais de alarme, agrupados como dengue não clássico (Tabela 2). Quanto a outros métodos de diagnóstico laboratorial, 335 (39,4\%) casos também realizaram a sorologia para dengue (Tabela 1 ), sendo que $302(35,5 \%)$ apresentaram resultado reagente, $32(3,8 \%)$ não reagente e um $(0,1 \%)$ foi inconclusivo. Em 386 casos também foi realizado o teste rápido NS1, sendo que para $369(43,4 \%)$ o teste foi reagente.

O DENV-4 foi o sorotipo identificado no maior percentual de casos negativos para o teste rápido NS1 $(10,6 \%)$ e sorologia $(12,1 \%)$. Os sorotipos DENV-2 e DENV-3 não foram avaliados quanto ao NS1, porque, nos anos quando estes circularam no município de Belo Horizonte, o teste rápido não era utilizado todavia.

Entre os casos que realizaram isolamento viral e/ou RT-PCR, nove (1,1\%) se enquadravam nas classificações de casos graves. Destes, sete apresentaram manifestações 
Tabela 2 - Classificação e caracterização por sexo e idade dos casos confirmados por sorotipo do vírus da dengue, Belo Horizonte, Minas Gerais, 2009-2014

\begin{tabular}{|c|c|c|c|c|c|c|}
\hline \multirow[t]{2}{*}{ Classificação e características } & \multicolumn{4}{|c|}{$\begin{array}{c}\text { Sorotipos } \\
\mathrm{n}(\%)\end{array}$} & \multirow[t]{2}{*}{ Total $^{b}$} & \multirow[t]{2}{*}{ p-valor } \\
\hline & DENV-1 ${ }^{\mathrm{a}}$ & DENV-2 ${ }^{\mathrm{a}}$ & DENV-3a & DENV-4a & & \\
\hline \multicolumn{7}{|l|}{ Classificação dos casos } \\
\hline Dengue clássico & $442(99,1)$ & $64(95,5)$ & $52(98,1)$ & $160(98,8)$ & $718(98,6)$ & - \\
\hline Dengue 'não clássico' & $4(0,9)$ & $3(4,5)$ & $1(1,9)$ & $2(1,2)$ & $10(1,4)$ & - \\
\hline \multicolumn{7}{|l|}{ Sexo } \\
\hline Feminino & $266(51,8)$ & $46(55,4)$ & $30(45,5)$ & $106(56,4)$ & 448 & \multirow{2}{*}{0,416} \\
\hline Masculino & $248(48,2)$ & $37(44,6)$ & $36(54,5)$ & $82(43,6)$ & 403 & \\
\hline \multicolumn{7}{|l|}{ Faixa etária (em anos) } \\
\hline$\leq 10$ & $31(6,2)$ & $4(4,9)$ & $5(7,8)$ & $9(4,8)$ & 49 & \multirow{4}{*}{0,261} \\
\hline $11-30$ & $224(44,9)$ & $34(41,5)$ & $28(43,8)$ & $66(35,5)$ & & \\
\hline $31-50$ & $148(29,7)$ & $24(29,3)$ & $24(37,5)$ & $67(36,0)$ & 263 & \\
\hline$>50$ & $96(19,2)$ & $20(24,4)$ & $7(10,9)$ & $44(23,7)$ & 167 & \\
\hline
\end{tabular}

a) Sorotipos do vírus da dengue - 1,2,3 e 4 .

b) Totais variáveis devido à falta de informação da referida variável na fonte de informação.

c) Teste do qui-quadrado de Pearson.

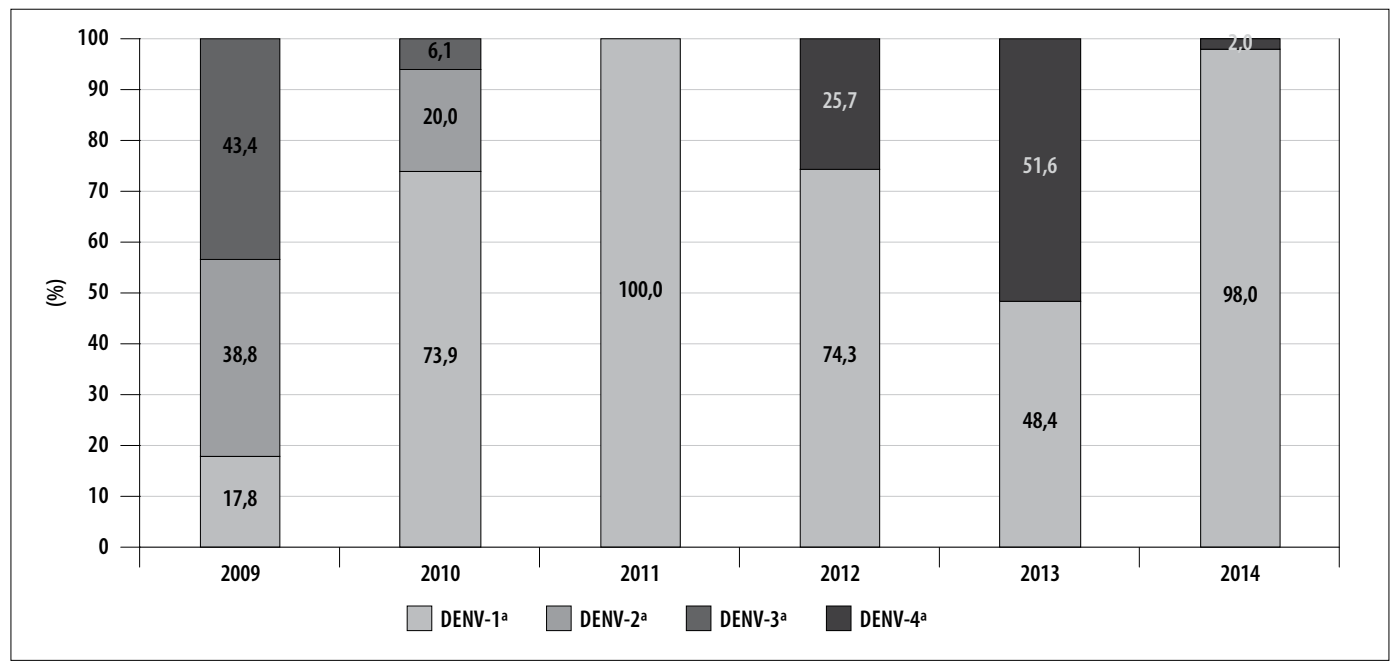

Figura 2 - Percentual dos sorotipos do vírus da dengue segundo 0 ano de início de sintomas, Belo Horizonte, Minas Gerais, 2009-2014

a) Sorotipos do vírus da dengue - $1,2,3$ e 4 .

hemorrágicas, dois apresentaram hematúria, e um, sangramento gastrointestinal.

Quanto à proporção de casos graves (não clássicos) e casos clássicos, o maior percentual de casos graves (casos não clássicos) foi identificado com o sorotipo DENV-2 (6,0\%); e com o sorotipo DENV-4 (98,8\%), foi identificado maior percentual de casos clássicos da doença.

Do total de casos do estudo, 47 (5,5\%) foram internados e três $(6,4 \%)$ necessitaram de cuidados em unidade de terapia intensiva (UTI). Do total de internados, $61,7 \%(n=29)$ foram do sexo feminino e $66,0 \%(n=18)$ apresentaram idade entre 11 e 50 anos. A média do tempo decorrido entre 0 início dos sintomas e a internação foi de 5 dias (DP \pm 5 ), sendo a mediana de 4 dias (intervalos interquartis [IQ] 3;6). A média de dias de permanência de internação foi de 3,8 dias (DP $\pm 2,3$ ), sendo a mediana de 3,0 dias (IQ 2,0;5,0). Entre os casos internados, em $61,7 \%(n=29)$ foi 


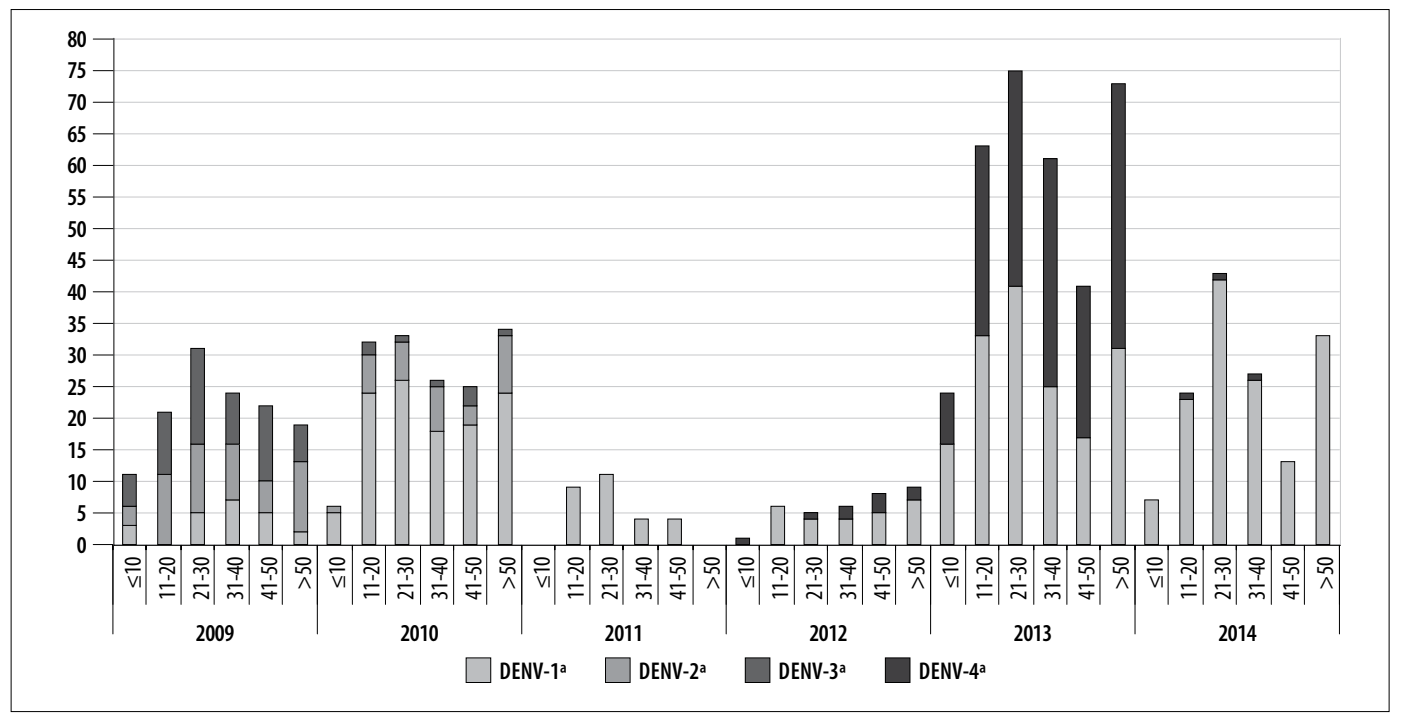

Figura 3 - Distribuição dos sorotipos do vírus da dengue por faixa etária e ano de início de sintomas, Belo Horizonte, Minas Gerais, 2009-2014

a) Sorotipos do vírus da dengue $-1,2,3$ e 4 .

identificado o sorotipo DENV-1; em 25,5\% ( $\mathrm{N}=12)$, o DENV-4; em 10,6\% $(n=5)$, o DENV-2; e em 2,1\% $(\mathrm{n}=1), 0$ DENV-3. Em relação ao uso de UTI, o maior percentual foi de casos com o DENV-4: 66,7\% $(n=2)$.

Quanto ao encerramento dos casos, 693 (89,1\%) foram encerrados por critério laboratorial e 85 por critério clínico-epidemiológico (10,9\%), apesar de o exame de identificação viral ter resultado positivo. Do total de casos que apresentaram o campo 'evolução' preenchido, 662 (99,0\%) evoluíram para cura, seis $(0,9 \%)$ foram a óbito por dengue e um $(0,1 \%)$ evoluiu a óbito por outras causas. 0 maior número absoluto de óbitos por dengue $(n=4)$ ocorreu em pessoas com 0 sorotipo DENV-1. Um caso com o sorotipo DENV-3 evoluiu a óbito por dengue e outro com o sorotipo DENV-4 evoluiu a óbito por outras causas.

\section{Discussão}

0 presente estudo, conduzido em Belo Horizonte, identificou, entre os casos de dengue notificados entre 2009 a 2014 e confirmados por isolamento viral e/ou RT-PCR, predominância do sorotipo DENV-1, circulante em todo o período avaliado, seguido por DENV-4, DENV-2 e DENV-3.

0 padrão de sorotipos de dengue circulantes acompanhou o padrão nacional, ${ }^{12} \mathrm{e}$ a positividade da identificação viral em Belo Horizonte mostrou-se abaixo da média nacional. No Brasil, em 2014, o percentual de positividade da identificação viral nas amostras enviadas para os laboratórios de referência foi de $36,8 \%,{ }^{13}$ e em 2015 , de 39,2\%. ${ }^{14}$ Neste estudo, entre as amostras testadas, o maior percentual de soropositivos foi de $28,0 \%$ em 2013, ano epidêmico, com circulação de DENV-1 e DENV-4. Estudo conduzido em Cuiabá, capital do estado de Mato Grosso, de 2010 a 2014, também observou baixo percentual de positividades sendo 20120 ano com o maior percentual de casos positivos $(23,1 \%) .{ }^{15}$

No presente estudo, o sexo feminino foi predominante em todos os sorotipos, em concordância com os achados encontrados por Martins et al. para Salvador, capital do estado da Bahia, no período de 2007 a 2014. ${ }^{16}$

Ao agrupar todos os casos em casos clássicos e casos não clássicos, observou-se que o percentual de casos classificados como não clássicos (DCC, FHD, SCD, DSCA e DG) supera em quase cinco vezes o observado no Sinan municipal para o mesmo período, quando $0,3 \%$ dos casos foram não clássicos. Estudo realizado em hospital público do Rio de Janeiro, RJ, no ano de 2008, durante uma das maiores epidemias registradas no município, encontrou o percentual de $6,7 \%$ de casos não clássicos. ${ }^{17}$

O DENV-2 foi o sorotipo com maior percentual de casos graves, neste estudo. Nos sorotipos DENV-4 e DENV-2; foram identificados maiores percentuais de casos internados. Estes achados corroboram os de 
Burattini et al., ${ }^{18}$ em pesquisa de abrangência nacional, ao observarem maior proporção de hospitalização relacionada à infecção pelo sorotipo DENV-2.

A distribuição das internações quanto ao sexo e faixa etária deu-se de maneira similar aos casos reportados em outras localidades e períodos. Entre 1997 e 2002, em Belo Horizonte, foi reportado maior percentual de internação de casos suspeitos de dengue entre pessoas do sexo feminino $(53,0 \%) \cdot{ }^{19}$ Os achados do trabalho em tela corroboram os desse estudo anterior, segundo o qual $60,4 \%$ dos casos internados eram de sexo feminino. Quanto à faixa etária, entre 1997 e 2002, em Belo Horizonte, a maior proporção de internação por dengue deu-se entre 19 e 59 anos $(65,0 \%),{ }^{19}$ enquanto na capital do estado de Goiás, Goiânia, na epidemia de 2013, o maior percentual de internações foi de pessoas com idade entre 21 e 50 anos (45,8\%) ou mais velhas $(27,1 \%)$ - a principal faixa etária internada foi acima de 50 anos $(37,5 \%){ }^{20}$

Campos, ${ }^{21}$ em estudo sobre Minas Gerais, observou que a internação ocorreu, em média, após quatro dias do início dos sintomas nas crianças e idosos, e após cinco dias do início da doença nos jovens e adultos. Os achados apresentados assemelham-se aos de Campos, segundo quem a média de dias de internação (dois dias ${ }^{21}$ foi quase a metade da observada neste estudo (3,8 dias de internação).

Destaca-se que nos anos avaliados, segundo dados do SIH/SUS, o percentual geral de internação por dengue em Belo Horizonte foi de 2,2\%, a passo que, segundo o presente estudo, foi de $5,5 \%$. 0 fato de 0 teste rápido NS1, utilizado na triagem de amostras para identificação viral, estar disponível em unidades de pronto atendimento (UPA) e hospitais, normalmente dedicados a atender casos mais graves, pode explicar o maior percentual de internação dos casos positivos para isolamento viral e/ou RT-PCR.

Em relação aos óbitos por dengue registrados no Sinan, no período e local estudados, o percentual de casos de dengue que evoluíram para óbito é de $0,02 \%$. 0 presente estudo encontrou um percentual 4,5 vezes maior $(0,9 \%)$, entre os casos com a variável 'evolução' preenchida. Tal resultado também pode ser explicado pela coleta de amostras para identificação viral em casos graves.

Quanto ao diagnóstico laboratorial realizado por outros métodos, do total de casos com isolamento viral e/ou RT-PCR positivo que também realizaram o NS1,
95,5\% apresentaram resultado positivo no teste rápido. 0 maior percentual de testes NS1 negativos correspondeu aos casos infectados pelo sorotipo DENV-4. Há relatos na literatura de que diferenças nas sensibilidades entre os sorotipos demonstram que o NS1 é menos sensível em detectar casos de DENV-4. ${ }^{22,23}$

No período de 2009 a 2014, o preenchimento das manifestações clínicas não era obrigatório para os casos clássicos de dengue. Pressupõe-se que os casos clássicos, em sua maioria, apresentam a sintomatologia clássica da doença (febre de início súbito, acompanhada de pelo menos dois dos seguintes sinais e sintomas: náusea/vômitos; exantema; mialgia/artralgia; cefaleia/ dor retro-orbital; petéquias/prova do laço positiva; leucopenia) ${ }^{1}$. Além do que, em anos epidêmicos, há grande dificuldade de preenchimento de fichas de notificação com número elevado de variáveis. ${ }^{24}$ Portanto, não foi possível analisar associações referentes às manifestações clínicas das pessoas e os diferentes sorotipos.

Entre os casos infectados pelo sorotipo DENV-1, 1,2\% apresentaram NS1 negativo, e entre os infectados pelo DENV-4, 10,6\% apresentaram o resultado desse exame igualmente negativo. Tal resultado enfatiza a importância do envio de percentual de amostras negativas pelo NS1 para tentativa de isolamento do vírus. Atualmente, 0 município de Belo Horizonte envia 10,0\% de amostras negativas, percentual semelhante ao encontrado quando avaliado o sorotipo DENV-4.

A técnica de linkage de dados possibilitou a utilização de informações complementares de diferentes bancos de dados, otimizando o tempo de trabalho e mostrando-se viável do ponto de vista operacional. 0 linkage determinístico apresenta maior especificidade; contudo, essa técnica pode "descartar" registros com potencial de pareamento, por apresentarem inconsistências ou erros de digitação. ${ }^{25}$ Já o linkage probabilístico aumenta a chance de pareamento, porém gera maior número de pares para revisão manual, sendo este seu principal problema descrito em outros trabalhos. ${ }^{26-28}$ Dada sua maior acurácia, foi definida a utilização do tipo determinístico neste estudo.

Como limitações desta investigação, ressalta-se a utilização de dados secundários, oriundos de bancos de dados com potencial de perdas, omissões e/ou registros incorretos. A técnica de linkage permitiu revisar essas bases, avaliar a completude das informações e analisar a dinâmica da circulação viral em Belo Horizonte. Ademais, para a realização dos exames de 
identificação do vírus, pode ocorrer viés de seleção, haja vista 0 teste utilizado para triagem de amostras estar disponível em UPAs e hospitais que costumam prestar assistência a casos mais graves. Outrossim, a técnica de isolamento viral é realizada até $05^{\circ}$ dia depois do início de sintomas, o que reduz o número de pessoas com amostra adequada para tal teste, considerando-se aqueles que demoram a buscar 0 serviço de saúde. 0 acondicionamento da amostra também interfere na possibilidade de realização de tal exame. ${ }^{29}$

0 preenchimento correto e com qualidade das notificações é essencial para estudos na área da Saúde, favorecendo a tomada de decisões. A falta de informações básicas referentes às manifestações clínicas na ficha de notificação impossibilita a análise mais aprofundada das características das infecções por diferentes sorotipos do DEN-V. Entretanto, conforme já foi comentado, em anos epidêmicos, o preenchimento de extensas fichas de notificação é praticamente inviável. ${ }^{24}$

Os achados do presente estudo ressaltam a importância das boas práticas de coleta, conservação e transporte das amostras, associadas à seleção adequada de casos

\section{Referências}

1. Ministério da Saúde (BR). Secretaria de Vigilância em Saúde. Coordenação-Geral de Desenvolvimento da Epidemiologia em Serviços. Guia de vigilância em saúde [Internet]. Brasília: Ministério da Saúde; 2016 [citado 2020 maio 19]. 773 p. Disponível em: https:// www.saude.gov.br/images/pdf/2016/agosto/25/GVSonline.pdf

2. Tauil P. L. Prefácio. In: Valle D, Pimenta DN, Cunha RV, organizadores. Dengue: teorias e práticas. Rio de Janeiro: Editora Fiocruz; 2015. p. 11-13.

3. Secretaria Municipal de Saúde (Belo Horizonte). Balanço da dengue [Internet]. Belo Horizonte: Secretaria Municipal de Saúde; 2018 [citado 2018 jan 8]. Disponível em: http://www.pbh.gov.br/smsa/ dengue/balanco_dengue.php

4. Pessanha JEM, Caiaffa WT, Kroon EG, Proietti FA. Dengue em três distritos sanitários de Belo Horizonte, Brasil: inquérito soroepidemiológico de base populacional, 2006 a 2007. Rev Panam Salud Publica [Internet]. 2010 [citado 2020 maio 19];27(4):252-8. Disponível em: https://scielosp.org/pdf/rpsp/2010.v27n4/252-258/pt em tempo oportuno, atendendo aos critérios para identificação viral. São ações viáveis para implementação, de potencial impacto positivo na identificação do sorotipo e acompanhamento da dinâmica da dengue.

Reitera-se a importância de analisar e descrever características das infecções pelos diferentes sorotipos do DENV. A história recente de dengue em Belo Horizonte e os cenários epidemiológicos/entomológicos atuais determinam maior susceptibilidade da ocorrência de novas epidemias, destacando ser fundamental aprofundar o conhecimento da doença e fornecer informações que possam auxiliar o desenho de políticas de Saúde Pública mais efetivas.

\section{Contribuição dos autores}

Amâncio FF, Ferraz ML, Carneiro M e Oiko CSF contribuíram na concepção e delineamento do artigo, análise e interpretação dos resultados, redação e revisão do manuscrito. Todos os autores aprovaram a versão final e são responsáveis por todos os aspectos do trabaho, incluindo a garantia de sua precisão e integridade.
5. Fundação Ezequiel Dias - FUNED. Gal [Internet]. Belo Horizonte; FUNED; 2018 [citado 2018 jan 21]. Disponível Em: Http://Www.Funed.Mg.Gov.Br/Tag/Gal/

6. Bartholomay P, Oliveira GP, Pinheiro RS, Vasconcelos AMN. Melhoria da qualidade das informações sobre tuberculose a partir do relacionamento entre bases de dados. Cad Saúde Pública [Internet]. 2014 nov [citado 2020 maio 19];30(11):2459-70. Disponível em: http://dx.doi.org/10.1590/0102-311X00116313

7. Soeiro CMO, Miranda AE, Saraceni V, Santos MC, Talhari S, Ferreira LCL. Syphilis in pregnancy and congenital syphilis in Amazonas State, Brazil: an evaluation using database linkage. Cad Saúde Pública [Internet]. 2014 abr [citado 2020 maio 19];30(4):715-23. Disponível em: http://dx.doi. org/10.1590/0102-311X00156312

8. Oliveira GP, Bierrenbach ALS, Camargo Júnior KR, Coeli CM, Pinheiro RS. Acurácia das técnicas de relacionamento probabilístico e determinístico: o caso da tuberculose. Rev Saúde Pública [Internet]. 2016 ago [citado 2020 maio 19];50:49. Disponível em: https://doi.org/10.1590/\$1518-8787.2016050006327 
9. Rosselto EV, Luna EJA. Relacionamento entre bases de dados para vigilância da pandemia de influenza A(H1N1) pdm09, Brasil, 2009-2010. Cad Saúde Pública [Internet]. 2016 jul [citado 2020 maio 19];32(7):e00014115. Disponível em: https://doi. org/10.1590/0102-311X00014115

10. Instituto Brasileiro de Geografia e Estatística - IBGE Síntese: Belo Horizonte [Internet]. Rio de Janeiro: Instituto Brasileiro de Geografia e Estatística; 2017 [citado 2017 dez 17]. Disponível em: https://cidades. ibge.gov.br/brasil/mg/belo-horizonte/panorama

11. Plataforma Devmedia. SQL JOIN: entenda como funciona o retorno de dados. [Internet]. [S.I.]: Plataforma Devmedia; 2014 [citado $2020 \mathrm{fev}$ 11]. Disponível em https://www.devmedia.com.br/sql-joinentenda-como-funciona-o-retorno-dos-dados/31006

12. Teixeira MG, Siqueira Júnior JB, Ferreira GLC, Bricks L, Joint G. Epidemiological trends of dengue disease in Brazil (2000-2010): a systematic literature search and analysis. PLoS Negl Trop Dis [Internet]. 2013 Dec [cited 2020 May 19];19(7):e2520. Available from: https://doi.org/10.1371/journal.pntd.0002520

13. Ministério da Saúde (BR). Secretaria de Vigilância em Saúde. Dengue: monitoramento até a Semana Epidemiológica (SE) 32 de 2014. Bol epidemiol [Internet]. 2014 [citado 2018 mar 5];45(19):1-6. Disponível em: http://portalarquivos2.saude.gov.br/ images/pdf/2014/setembro/01/Boletim-DengueSE32.pdf

14. Ministério da Saúde (BR). Secretaria de Vigilância em Saúde. Monitoramento dos casos de dengue, febre de chikungunya e febre pelo vírus Zika até a Semana Epidemiológica 48, 2015. Bol Epidemiol [Internet]. 2015 [citado 2018 mar 5];46(44):1-9. Disponível em: http://portalarquivos2.saude.gov.br/images/pdf/2016/ janeiro/07/2015-svs-be-pncd-se48.pdf. Acesso em 05 de março de 2018

15. Governo do Mato Grosso. Secretaria de Estado de Saúde. Diagnóstico laboratorial específico e nova classificação da dengue [Internet]. Cuiabá: Secretaria de Estado de Saúde ; 2015 [citado 2019 mar 5]. Disponível em: http://www.telessaude.mt.gov.br/ Arquivo/Download/2075

16. Martins MMF, Almeida AMFL, Fernandes NDR, Silva LS, Lima TB, Orrico AS, et al. Análise dos aspectos epidemiológicos da dengue na microrregião de saúde de Salvador, Bahia, no período de 2007 a 2014. Rev Espaço Saúde [Internet]. 2015 out-dez [citado 2020 maio 19];16(4):64-73. Disponível em: http://www.uel. br/revistas/uel/index.php/espacoparasaude/article/ download/23300/9

17. Escosteguy CC, Pereira AGL, Medronho RA, Rodrigues CS, Chagas KKF. Diferenças, segundo faixa etária, do perfil clínico-epidemiológico dos casos de dengue grave atendidos no Hospital Federal dos Servidores do Estado, Rio de Janeiro-RJ, Brasil, durante a epidemia de 2008. Epidemiol Serv Saúde [Internet]. 2013 mar [citado 2020 maio 19];22(1):67-76. Disponível em: https://doi.org/10.5123/S1679-49742013000100007

18. Burattini MN, Lopez LF, Coutinho FAB, Siqueira Júnior JB, Homsani S, Sarti E, et al. Age and regional differences in clinical presentation and risk of hospitalization for dengue in Brazil, 2000-2014. Clinics [Internet]. 2016 ago [citado 2020 maio 19];71(8):455-63. Disponível em: http://dx.doi. org/10.6061/clinics/2016(08)08

19. Duarte HH, França EB. Data quality of dengue epidemiological surveillance in Belo Horizonte, Southeastern Brazil. Rev Saúde Pública [Internet]. 2006 fev [citado 2020 maio 19]; 40(1):134-42. Disponível em: http://dx.doi.org/10.1590/S003489102006000100021

20. Nascimento LB, Oliveira PS, Magalhães DP, França DDS, Magalhães ALA, Silva JB, et al. Caracterização dos casos suspeitos de dengue internados na capital do estado de Goiás em 2013: período de grande epidemia. Epidemiol Serv Saúde [Internet]. 2015 jul-set [citado 2020 maio 19];24(3):475-484. Disponível em: http://dx.doi.org/10.5123/S167949742015000300013

21. Campos KB. Características clínico-epidemiológicas dos casos graves e óbitos por dengue, minas gerais, 2008 a 2010. Belo Horizonte, 2012 [dissertação]. Belo Horizonte: Universidade Federal de Minas Gerais; 2012. Disponível em: https://repositorio.ufmg.br/ handle/1843/BUOS-8ZKMJZ

22. Bessoff K, Delorey M, Sun W, Hunsperger E. Comparison of two commercially available dengue virus (denv) ns1 capture enzyme-linked immunosorbent assays using a single clinical sample for diagnosis of acute denv infection. Clin Vaccine Immunol [Internet]. 2008 Oct [cited 2020 May 19];15(10):1513-8. Available from: https://doi. org/10.1128/cvi.00140-08

23. Mcbride WJH. Evaluation of dengue ns1 test kits for the diagnosis of dengue fever. Diagn Microbiol Infect Dis [Internet]. 2009 May [cited 2020 May 19];64(1):31-6. Available from: https://doi. org/10.1016/j.diagmicrobio.2009.01.002 
24. Barbosa JK, Barrado JCS, Zara ALSA, Siqueira Júnior JB. Avaliação da qualidade dos dados, valor preditivo positivo, oportunidade e representatividade do sistema de vigilância epidemiológica da dengue no Brasil, 2005 a 2009. Epidemiol Serv Saúde [Internet]. 2015 jan-mar [citado 2020 maio 19];24(1):49-58. Disponível em: https://doi.org/10.5123/S167949742015000100006

25. Sayers A, ben-Shlomo Y, Blom AW, Steele F. Probabilistic record linkage. Int J Epidemiol [Internet]. 2015 Jun [cited 2020 May 19];45(3):95464. Available from: https://doi.org/10.1093/ije/dyv322

26. Capuani L, Bierrenbach AL, Abreu F, Takecian PL, Ferreira JE, Sabino EC. Accuracy of a probabilistic record-linkage methodology used to track blood donors in the Mortality Information System database. Cad Saúde Pública [Internet]. 2014 Aug [cited 2020 May 19];30(8):1623-32. Available from: https://doi. org/10.1590/0102-311X00024914

\section{Abstract}

objective: to describe dengue virus circulation in Belo Horizonte, Brazil, from 2009 to 2014. Methods: this is a series study of cases of dengue infected by different virus serotypes, identified by virus isolation or RT-PCR; database linkage was performed between the Notifiable Health Conditions Information System (SINAN), the Brazilian National Health System Hospital Information System (SIH/SUS) and the Laboratory Environment Manager (GAL). Results: $91.1 \%$ of the records were linked $(n=775) ;$ among the cases $(n=851), 60.4 \%(n=514)$ were confirmed as DENV-1, 22.1\% ( $n=188) D E N V-4$, 9.8\% ( $n=83)$ as DENV-2, and $7.7 \%(n=66)$ as DENV-3; DENV-2 accounted for a higher percentage of severe cases (4.5\%). Conclusion: DENV-1 prevailed and circulated in all evaluated years.

Keywords: Dengue; Dengue Virus; Epidemiological Monitoring; Database.
27. Camargo Júnior KR, Coeli CM. RecLink 3: nova versão do programa que implementa a técnica de associação probabilística de registros (probabilistic record linkage). Cad Saúde Coletiva. 2006 abrjun;14(2):399-404.

28. Coeli CM, PinheiroRS, Camargo Júnior KR. Conquistas e desafios para o emprego das técnicas de record linkage na pesquisa e avaliação em saúde no Brasil. Epidemiol Serv Saúde [Internet]. 2015 out-dez [citado 2020 maio 19];24(4):795-802. Disponível em: http:// dx.doi.org/10.5123/\$1679-49742015000400023

29. Fundação Ezequiel Dias - FUNED. Manual de coleta, acondicionamento e transporte de material biológico para exames laboratoriais [Internet]. Belo Horizonte: Fundação Ezequiel Dias; 2018 [citado 2020 maio 19]. 161 p. Disponível em: http://www.funed.mg.gov.br/wpcontent/uploads/2018/10/manual_coleta_amostras_ biologicas_Funed.pdf

\section{Resumen}

objetivo: describir la circulación viral del dengue en Belo Horizonte, Brasil, de 2009 a 2014. Métodos: se trata de estudio de una serie de casos de dengue infectados por diferentes serotipos del virus, identificados por aislamiento viral o RT-PCR; se realizó una conexión con las bases de datos del Sistema de Información para Enfermedades de Notificación (Sinan), el Sistema del Información Hospitalaria del Sistema Único de Salud (SIH/SUS) y el Gestor de Ambiente de Laboratorio (GAL). Resultados: fueron relacionados $91,1 \%$ de los registros $(n=775)$; entre los casos $(n=851)$, el 60,4\% $(n=514)$ fue confirmado como DENV-1, 22,1\% $(n=188)$ como DENV-4, 9,8\% ( $n=83)$ como DENV-2 y 7,7\% ( $n=66)$ como DENV-3; DENV-2 tuvo un mayor porcentaje de casos graves (4,5\%). Conclusión: DENV-1 prevaleció y circuló en todos los años evaluados.

Palabras clave: Dengue; Virus del Dengue; Monitoreo Epidemiológico; Base de Datos.

Recebido em 10/12/2019

Aprovado em 24/04/2020 